\title{
The user-friendly, ergonomic design aspect of recent intraoral scanners: a literature review
}

\author{
Hye-Nan Park', Won-Hee Kim¹, Young-Jun Lim², Won-Jin Lee ${ }^{3}$, Jung-Suk Han², Seung-Pyo Lee* \\ 'Department of Oral Anatomy, School of Dentistry, Seoul National University, Seoul, Republic of Korea \\ ${ }^{2}$ Department of Prosthodontics and Dental Research Institute, School of Dentistry, Seoul National University, Seoul, Republic \\ of Korea \\ ${ }^{3}$ Department of Oral Maxillofacial Radiology, School of Dentistry, Seoul National University, Seoul, Republic of Korea
}

Recently, traditional impression has been rapidly replaced by digital impression using intraoral scanning. There are more than 7 types of intraoral scanners available in the dental market. It is difficult to make effective strategic choices due to a lack of standards and guidelines for optimal intraoral scanning devices. So far, little has been reported about evaluating the ergonomic aspect of these scanners. This literature review compares current intraoral scanning systems based on different types of handles and suggests the most comfortable, user-friendly intraoral scanners from an ergonomic standpoint. (J Dent Rehabil Appl Sci 2015;31(3):221-30)

Key words: intraoral scanner; ergonomics; handle; user-friendly design

\section{서론}

1973년 프랑스의 Dr. Francois Duret가'optical impression' 이라는 제목으로 $\mathrm{CAD} / \mathrm{CAM}$ 의 치의학 적 용 방법론을 발표한 이후 치의학 분야에서의 디지털 기 술 적용은 계속 시도되고 있다. 특히 치과진료 중 인상 (impression making)분야에 디지털 기술이 적용되며 전 통적인 인상 방식의 불편함과 단점을 극복하게 되었다. 인상재를 사용하는 대신 $3 \mathrm{D}$ 스캐너를 사용하여 치아 표 면의 이미지를 보여주게 되어 이제는 실제적이고 실시간 적인 치아 형태를 보여주는 새로운 구내스캐너 시스템이 소개되었다.

현재, 전 세계 의료시장에 소비자들이 선택할 수 있는 $3 \mathrm{D}$ 구내스캐너들이 10 가지 이상이 있다. 하지만 기술이 빠르게 발전하는 가운데 사용자(치과의사)가 다양한 제

*Correspondence to: Seung-Pyo Lee

Professor, Department of Oral Anatomy, School of Dentistry, Seoul National University, 103, Daehak-ro, Jongno-gu, Seoul, 03080, Republic of Korea Tel: +82-2-740-8671, Fax: +82-2-762-6671, E-mail: orana9@snu.ac.kr Received: May 8, 2015/Last Revision: July 20, 2015/Accepted: July 27, 2015
품들 중 스캐너의 기술과 인체공학적 디자인 두 요소를 모두 충족할 수 있는 선택의 기준이 모호하다.

여기서 말하는 'Ergonomics' 인체공학이라는 단어는 고대그리스 어원에 따르면 'ergo'는 work 즉, 일, 업무, 노동 등의 뜻이며, 'nomic'은 자연적 법칙과 시스템을 말 한다. 과거 인류의 어원을 살펴밨을 때 자연의 법칙을 기 본으로 하여 도구의 사용성, 효율성, 안전성 모두를 고려 함을 알 수 있다. ${ }^{1}$ 도구의 디자인 과정에서 자연의 법칙, 즉 자연적인 인체의 구조와 과학적 요소가 결합하여 사 람들이 도구를 안전하고 효율적으로 사용할 수 있도록 한다. ${ }^{2}$ 인체공학은 도구의 원활한 사용을 위해 인간의 인 체 구조뿐만 아니라 도구가 가지는 시스템에 적용된 이 론, 원리, 데이터 등의 과학적인 원리 이해를 필요로 한 다. 이러한 원리는 치의학 분야의 많은 도구 제작에도 적 용되고 있다.

Copyright@ 2015 The Korean Academy of Stomatognathic Function and Occlusion. (c) It is identical to Creative Commons Non-Commercial License. 


\section{1. 치의학 분야의 인체공학적 현상과 문제점}

근골격장애(musculoskeletal disorder, MSD)는 인체에 명백한 위험요소이다. 특히 치의학분야에서 근골격장애 발생률이 매우 높아 인체공학에 기반한 근골격의 질환 과 장애에 대한 예방이 매우 필요하다. 더불어 성공적인 인체공학적 디자인의 제품은 사용자의 생산성을 높이고 잠정적인 질환과 질병을 피할 수 있으며, 사용자로부터 큰 만족도를 얻을 수 있다.

일반적인 일터에서의 위험요소는 어색한 자세로 힘을 반복적으로 주거나, 무거운 물체를 빈번하게 들어 올리 고, 혹은 당기거나 미는 행동이다. ${ }^{2}$ 손가락과 손목의 거 듭되는 구부림과 팽창(늘림)의 반복적인 행동은 손 장애 를 유발한다. 특히나, 직업 군 별 고통의 체감에 대한 실 험에 따르면 치과보철과, 구강외과, 치과보존과, 치주과 등을 전공하는 치과의사들에게서 손가락과 손목에 대 한 통증 발생이 더 빈번하다(Table 1). ${ }^{3}$ 따라서 이러한 점 을 감안한 치과용 기구의 개발이 필요하다. 특히 구내스 캐너의 경우 크기와 무게가 여타 치과용 장비에 비해 더 크고 무거우며 아직 많은 수의 치과의사들이 사용해보 지 않은 상황이어서 인체공학적 디자인이 더욱 요구되 고 있다.

\section{2. 스캐너의 형태에 따른 분류}

현재 시중에 나와 있는 7 가지 제품들을 핸들의 대표적 인 3가지 형태에 따라 분류할 수 있다. 첫 번째는 총 타입 (gun type), 두 번째는 핸들 타입(handle type), 세 번째는 펜 타입(pen type)이다(Fig. 1 - 3). ${ }^{4-10}$ 각각의 타입 별 스 캔의 원리와 그에 따른 그립의 형태를 알아볼 수 있다.

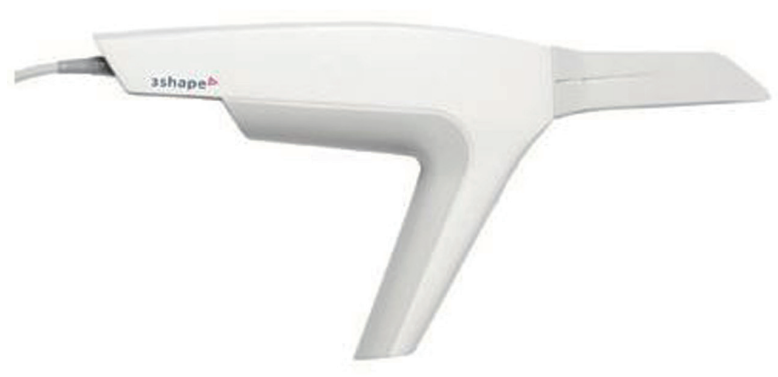

Fig. 1. Gun type Scanner. ${ }^{4}$

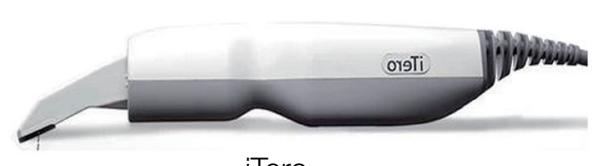

iTero

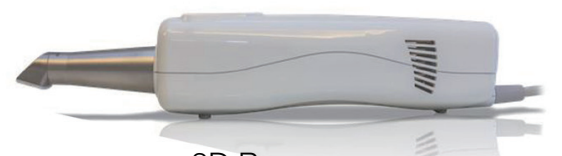

3D Progress

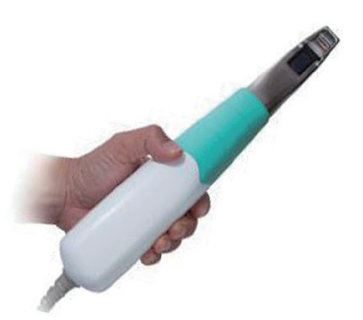

IOS Fastscan

Fig. 2. Handle type Scanners. ${ }^{5-7}$

Table 1. Awareness of ergonomics according to different specialties ${ }^{3}$

\begin{tabular}{|c|c|c|c|c|c|c|c|}
\hline \multirow{2}{*}{$\begin{array}{l}\text { Characteristics } \\
\text { Specilaties }\end{array}$} & \multirow[t]{2}{*}{ No. } & \multicolumn{2}{|c|}{ Pain } & \multicolumn{2}{|c|}{$\begin{array}{l}\text { Pain in more than } \\
\text { one park of body }\end{array}$} & \multicolumn{2}{|c|}{$\begin{array}{l}\text { Awareness of } \\
\text { ergonomics }\end{array}$} \\
\hline & & Mean & $\mathrm{SD}$ & Mean & $\mathrm{SD}$ & Mean & SD \\
\hline Endodontics & 55 & 0.66 & 0.476 & 0.00 & 0.000 & 0.37 & 0.488 \\
\hline Oral surgery & 98 & 0.68 & 0.474 & 0.17 & 0.375 & 0.49 & 0.502 \\
\hline Prosthodontics & 106 & 0.83 & 0.375 & 0.33 & 0.474 & 0.61 & 0.490 \\
\hline Periodontology & 47 & 0.60 & 0.493 & 0.20 & 0.402 & 0.35 & 0.483 \\
\hline General practitioners & 85 & 1.00 & 0.000 & 1.00 & 0.000 & 0.20 & 0.399 \\
\hline$P$ value & & \multicolumn{2}{|c|}{$0.000 *$} & \multicolumn{2}{|c|}{$0.000^{*}$} & \multicolumn{2}{|c|}{$0.000^{*}$} \\
\hline
\end{tabular}

* Significant. 


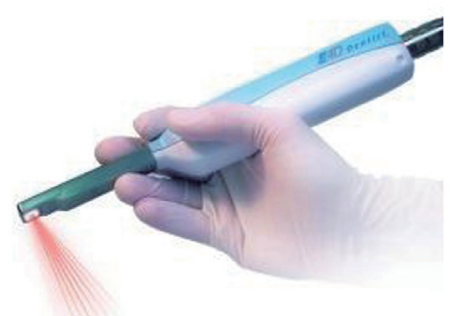

E4D Dentist

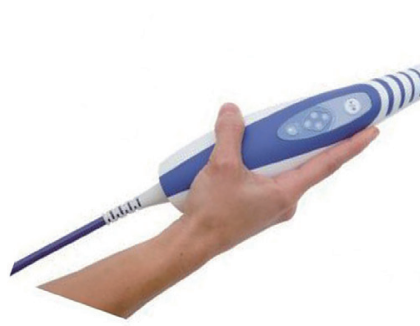

Lava C.O.S

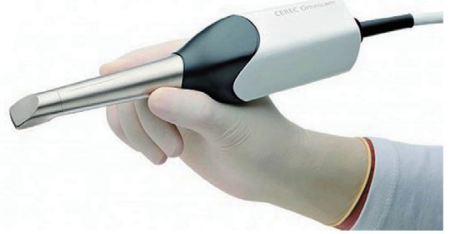

Cerec Omnicam

Fig. 3. Pen type Scanners. ${ }^{8-10}$

\section{(1) 총 타입 (Gun type)}

총 타입의 핸들을 가진 대표적인 스캐너는 TRIOS (3Shape A/S, Copenhagen, Denmark)이다. 이 스캐너 는 전체 기기의 크기는 $45 \times 113 \times 50 \mathrm{~cm}$ 이며, 무게는 약 $45 \mathrm{~kg}$ 이다. ${ }^{11}$ 사용되는 스캔의 원리는 공초점 레이저 현미경(confocal laser scanner microscopy, CLSM)이다. 이 원리는 선택된 깊이에서의 집중된 영상을 얻을 수 있 는 기술로 광학 절편(optical sectioning)이라고 알려진 과정을 거친다. ${ }^{12}$ 그립의 유형에 따라 구분해 보았을 때, 일반적인 그립 형태에 포함되지 않는 특수한 경우로 분 리 할 수 있다.

총 타입의 핸들을 가진 도구는 대표적으로 용접기 를 예로 들 수 있다(Fig. 4). Ergowelder 핸들은 기존의 torch 핸들 형태와 다르게 새롭게 그립 형태가 변형되었 다. 변형된 핸들은 Fig. 4의 권총 손잡이 형태인 총 타입 핸들로 출시되었다. 이로써, 용접공들은 도구를 장시간 사용할 때 손에 가해지는 부담을 최소화하며 보다 최적 의 자세로 일할 수 있다.

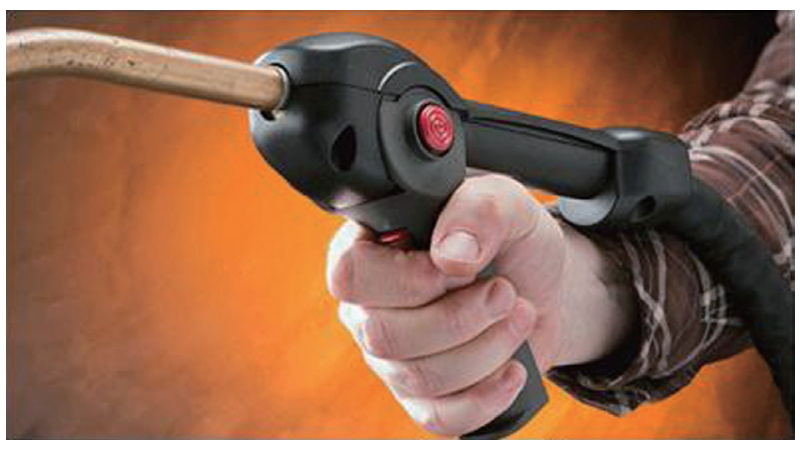

Fig. 4. Welder. ${ }^{13}$
이러한 인체공학적 핸들은 'MIG/MAG Welding'의 해서 소개되었다. 그 과정에서 새롭게 적용된 두 가지 요소가 핸들의 위치와 권총 형태의 그립이다. 개발자에 따르면, 총 타입의 Ergowelder 핸들은 기존의 torch 핸 들에 비해 효율적으로 용접공들의 어깨 통증을 줄여준 다고 한다. ${ }^{13}$

\section{(2) 핸들 타입 (Handle Type)}

핸들 타입에 해당하는 제품은 공초점 레이저 현미경 원리를 사용한 iTero (CADENT Ltd., Yehuda, Israel), 3D Progress (MHT optic research AG, Verona, Italy) 와 삼각법 원리(triangulation technique)를 사용한 IOS FastScan (IOS Technologies, Inc., San Diego, CA, USA) 제품으로 총 3 가지이다.

첫 번째 iTero는 기기 전체의 크기로 가로 $\times$ 세로 $\times$ 너비 순서로 $65.5 \times 135 \times 38 \mathrm{~cm}$ 이며, 무게는 약 $53 \mathrm{~kg}$ 이상이다. ${ }^{14}$ 두 번째 제품인 3D Progress의 스캐너 핸들 의 크기는 $30 \times 5 \times 6.5 \mathrm{~cm}$ 이며, 무게는 약 $2.74 \mathrm{~kg}$ 이다 ${ }^{15)}$. 핸들타입의 마지막 제품인 IOS FastScan은 전체 기 기의 크기로 $45 \times 45 \times 120 \mathrm{~cm}$ 이며, 전체 무게는 약 38 $\mathrm{kg}$, 핸들 무게는 약 $0.54 \mathrm{~kg}$ 이다. ${ }^{16}$

삼각법이란 물체의 형태에 대한 3차원 데이터를 모으 고 3차원 모델을 만드는데 사용되는 비접촉성 기술 중 하나이다. ${ }^{17}$ 첫 번째 능동적(active) 삼각법과 두 번째 수 동적(passive) 삼각법이 있고 이 두 방식 모두 사용된다. 능동적 삼각법은 레이저에 의해 생성된 빛 광선이 거울 에 반사되어 원하는 물체를 비추어 위치를 계산한다. ${ }^{18}$ 수동적 삼각법에서는 스캐너에서 직접 빛을 방출하지 않고 반사된 주위의 빛을 탐지해 낸다. 
그립의 유형은 power 그립으로 손가락이 물건 주위 를 감싸고 엄지손가락으로 그 위를 덮는 특징을 가진다. Power 그립을 사용하는 핸들이 가지는 특징은 손바닥에 서부터 손끝까지 모두 감쌀 수 있는 충분한 두께를 가진 다. 그 이유는 불편하게 힘을 주는 것을 막기 위해서 접 촉면이 넓어야 하기 때문이다(Fig. 5). ${ }^{19}$ Power 그립은 테 니스 선수가 라켓의 핸들을 잡는 형태를 예로 들 수 있 다. 이 그립은 손이 핸들에 고정되고 요수근관절과 팔의 큰 움직임을 가능하게 하므로 작은 움직임에는 적합하 지 않다. Holding retractors나 복부수술에 적합하다. ${ }^{20}$

Grooming 브러쉬는 일명 Coleman 브러쉬라고 알려 져 있다. Fig. 6 을 보면 이 브러쉬의 핸들은 세로로 길게 늘려져 있으며, 핸들과 목 부분(neck portion) 16은 연결 통로(transition)를 통하여 이어져 있다. 핸들의 윗면 20 은 목 부분 16 에서 시작하여 세로로 긴 아치형태의 표 면을 가진다 22. 핸들의 밑면 38은 반원 형태의 볼록 튀 어나온 경계 32 로 두 부분으로 나뉜다. 핸들의 끝부분은 둥그런 반구형과 컵 형태 26로 마무리 되어 있다. 핸들 12 은 인체공학적 grip-conforming 윤곽선을 가지고 있 다. 사실상, 핸들을 잡고 브러쉬를 사용할 때 필요로 하 는 손의 세부 부위는 대부분 손가락의 끝부분과 손바닥 이다. 그렇기 때문에 인체공학적 형태의 grooming 브러 쉬 핸들을 윤곽선에 따라 잡아 최소한의 힘으로 사용하 기 안전하다. ${ }^{21}$

Grooming 브러쉬에 더불어 weaving 나이프 핸들 (Fig. 7)의 경우 이전 형태의 나이프는 날카로운 모서리 의 핸들로 도구 사용시 사용자의 손을 베거나 멍 또는 찰과상을 유발시킬 수 있다. 그러므로 새롭게 디자인된 나이프 핸들의 모서리를 둥그렇게 함으로써 많은 위험 요소로부터 손을 보호할 수 있다. ${ }^{22}$

\section{(3) 펜 타입 (Pen type)}

펜 타입의 스캐너는 삼각법 원리를 사용하는 $\mathrm{CEREC}^{\circledR}$ Omnicam (Sirona Dental System GMBH, Bensheim, Germany), 활성 파면 샘플링 원리가 적용된 Lava C.O.S (3M ESPE, St. Paul, MN, USA)와 광결맞음 단층영상 법(optical coherent tomography, OCT) 원리를 적용한 E4D (D4D Technologies, LLS, Richardson, TX, USA) 제품이 있다.

$\mathrm{CEREC}^{\circledR}$ Omnicam의 전체 기기 크기는 $35 \times 121 \times 47$ $\mathrm{cm}$ 이며, 무게는 약 $38 \mathrm{~kg}$ 이다. ${ }^{23}$ Lava C.O.S 스캐너 핸들

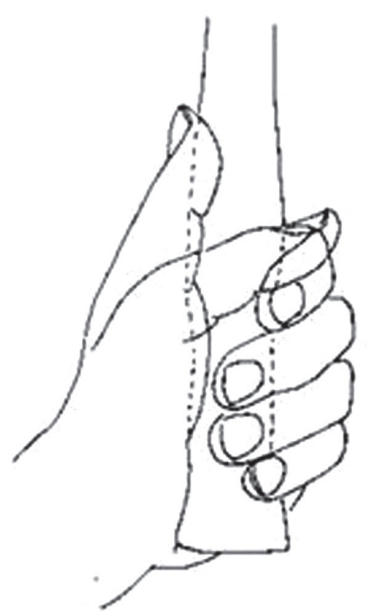

Fig. 5. Power grip. ${ }^{19}$
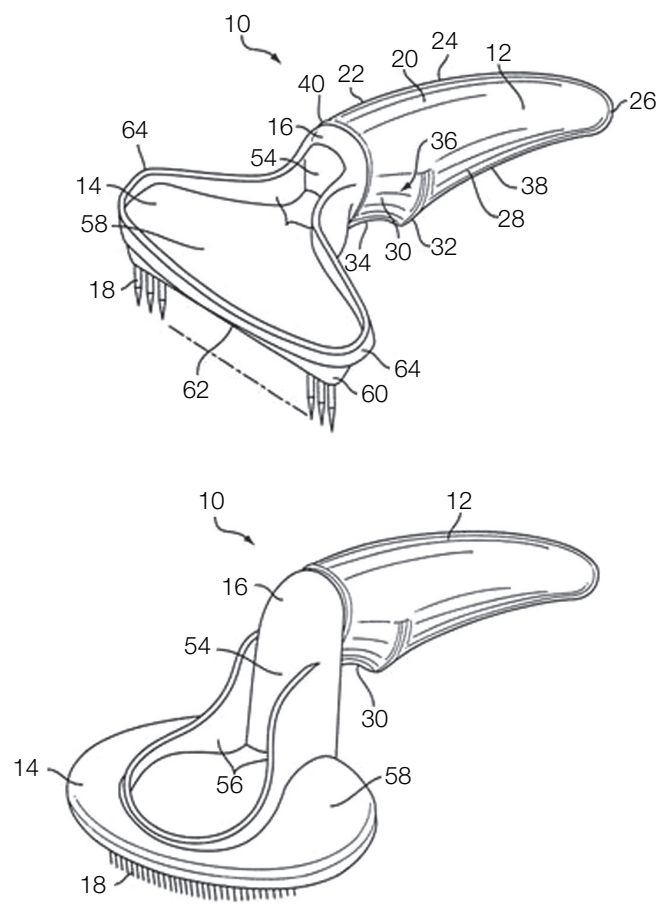

Fig. 6. Grooming brush. ${ }^{21}$
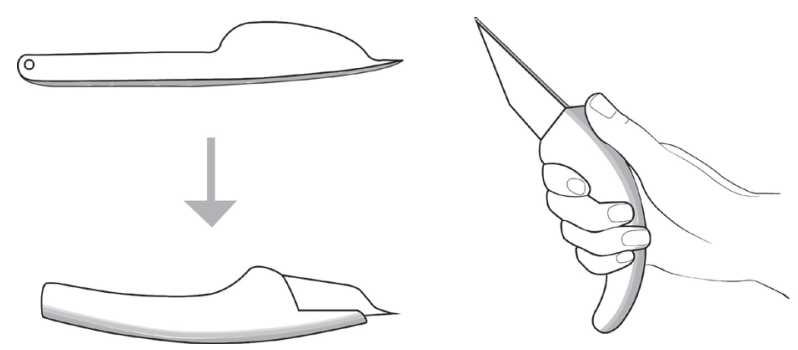

Fig. 7. Weaving Knife. ${ }^{22}$ 
의 크기는 $5.7 \times 5.7 \times 33 \mathrm{~cm}$ 이며, 무게는 $0.39 \mathrm{~kg}$ 이다. ${ }^{24}$

그립의 유형은 external precision 그립으로 글을 쓸 때 사용된다. 이 그립은 세 가지 요소를 포함한다. 첫 번째 는 pinch 그립이다. 이는 엄지와 검지손가락 사이로 작은 물건을 집을 때처럼 시작한다. 두 번째는 엄지손가락의 움푹 들어간 부분과 안쪽 테두리를 따라 손 전체를 지탱 할 수 있는 두 개의 추가요소를 가지고 있다. 이 타입은 미세수술이나, 초소형전자공학에 적합하다(Fig. 8). ${ }^{19,25}$

두 번째로 스캐너에 적용된 원리인 활성 파면 샘플링 은 3차원 이미지를 만드는 기술로 하나의 카메라와 활 성 파면 샘플링의 모듈만을 사용한다. AWS module의 가장 단순한 모습은 off-axis 조리개이며 광축을 주위로 원을 이루며 움직이게 된다. 이러한 움직임은 이미지 평

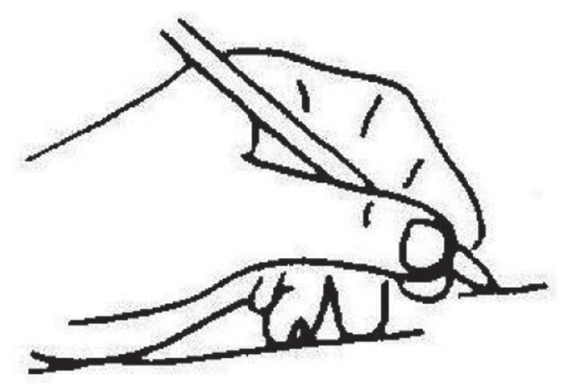

Fig. 8. External precision grip. ${ }^{19}$
면에 있는 원에 목표 지점의 회전을 생산한다. 목표 지 점의 깊이에 대한 정보는 각각의 점에서 만들어지며 원 을 이루고 있는 포인트 패턴들의 반지름으로부터 얻을 수 있게 되며, 이러한 것은 회전 하는 AWS module에 의 해 생성되고 있다. ${ }^{26}$

Fig. 9의 A는 일반적인 핸드피스의 한 종류를 보여주 며 stem hand 11, 플러그인 연결부분 12 , 목 부분(neck) 18 , 드라이브 헤드(drive head) 14 로 구성되어 있다. 최근 핸드피스 인체공학적 디자인 개발자는 기존의 핸드피스 에서 개선해야 할 점들을 확인했다. 1) Turbine unit, 2) Bearing unit, 3) Burr (drill)과 Chuck interengagement, 4) 전체적인 인체공학적 구조이다. 개발자가 4) 인체공 학적 구조를 기존 핸드피스 디자인의 개선해야 할 점으 로 언급했듯이, 최근 핸드피스의 목 부분이 재 디자인되 고 있다. 기존의 핸드피스의 목 부분은 Fig. 9의 A와 같 이 위로 볼록하게 구부러져 치아 간극이 어느 정도의 유 지되도록 디자인 되었다. 하지만 디자인이 새롭게 개선 되면서 $\mathrm{B}$ 와 같이 목 부분이 평편해지면서 최대의 치아 간극은 드라이브 헤드 바로 뒤가 되었다. ${ }^{27}$ 게다가 인체 공학적 이유들 때문에 핸드피스 핸들이 세로축 $11 \mathrm{a}$ 과 함께 일직선으로 되어야만 하므로 최대의 치아 틈새는 burr 길이로 제한되었다.

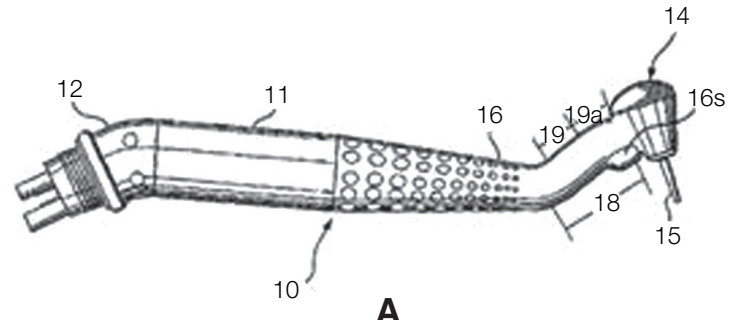

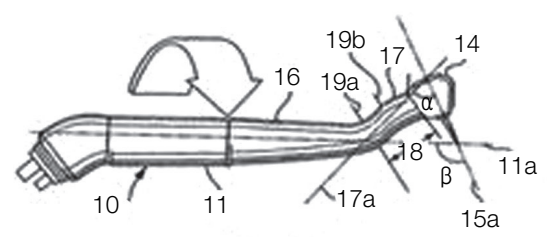

B

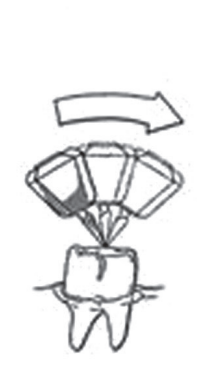

C

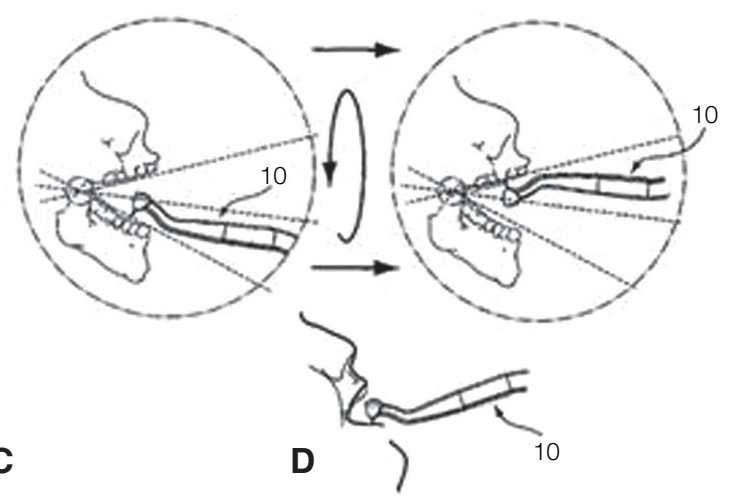

Fig. 9. Handpiece structure. ${ }^{27}$ (A) A perspective view of one embodiment of a handpiece in accordance with the present invention, (B) The ergonomics of a handpiece in accordance with the present invention, (C) Adjustment of the burr angle by rolling the ergonomic handpiece, (D) Large area of clearance between the bent portion. 
Fig. 10, 11 처럼 다른 특수한 경우의 핸들을 살펴보면 검지 손가락이 닿는 오목하게 들어간 홈 14 은 핸들 전체 의 앞 부분에 해당한다. 앞 면의 홈 14 은 검지 손가락을 지탱하기 위해 움푹 들어간 낮은 면을 가지고 있다. 검 지 손가락이 통과하는 끝 부분 12 도 둥그런 곡선형태를 가진다. Fig. 11 에서 검지 손가락은 앞 부분의 오목한 홈 14 에 반대로 힘을 주면서 검지 손가락이 옆으로 미끄러
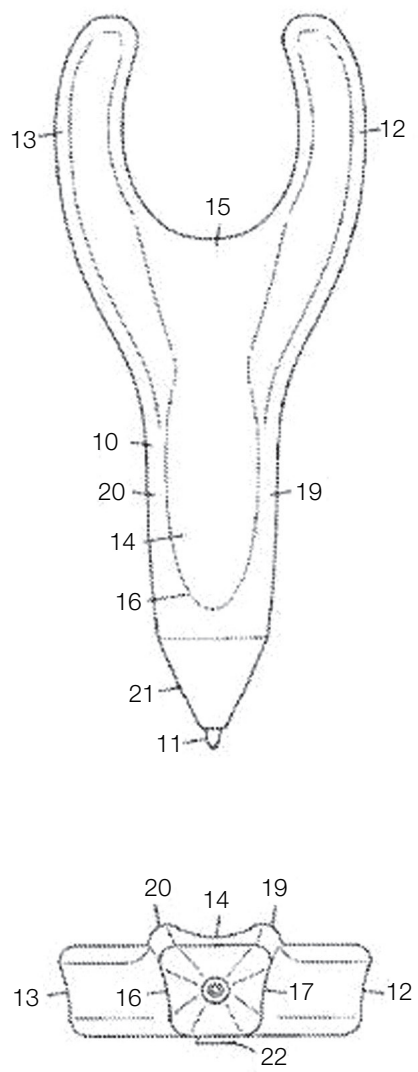

Fig. 10. Ergonomic handle design $1 .^{28}$

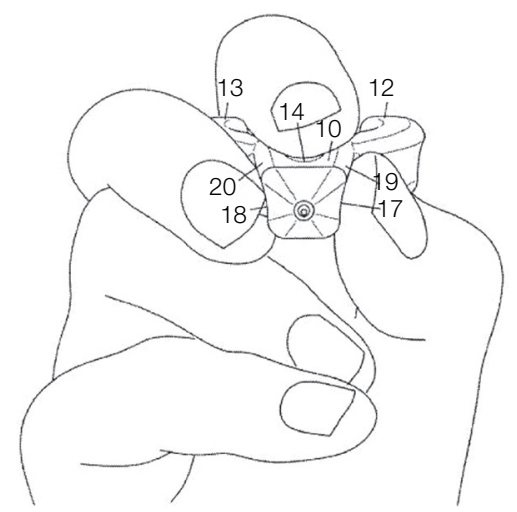

Fig. 11. Ergonomic handle design $2 .^{28}$
지는 것을 방지해준다. 엄지 손가락은 왼쪽 홈 17 에 반 대 되는 힘을 주게 된다. 이는 엄지와 검지 손가락의 힘 의 방향으로 미끄러지는 것을 방지한다. 중지 손가락은 오른쪽의 홈 18 에 반대되어 힘을 주게 된다. 이는 또한 중지 손가락이 검지 손가락의 방향인 위쪽으로 미끄러 지는 것을 방지한다. ${ }^{28}$

\section{3. 핸들의 고려사항}

\section{(1) 크기(Size)}

일반적인 사람들의 평균 손바닥 너비로 핸들을 감쌀 수 있는 핸들의 길이는 $10-15 \mathrm{~cm}$ 이다. 핸들의 굵기는 엄지손가락이 검지와 중지의 끝부분을 덮어야 한다. 성 인남성의 최대치의 힘을 위해서 핸들의 굵기는 지름 2.5 - $4 \mathrm{~cm}$ 가 되어야 한다(Fig. 12). ${ }^{19,29}$

\section{(2) 형태 (Shape)}

Fig. $13 \mathrm{~A}$ 는 원통 형태의 핸들이다. 이 형태의 핸들은 손에서 표시된 화살표 방향으로 닫혀진 손 안에서 미끄 러질 위험이 높다. 그렇기 때문에 첫 번째 핸들 형태의 제안은 손에서 미끄러짐을 예방하기 위해서 핸들의 중 앙을 두껍게 하는 것이다. 그 예가 양털 깎기의 핸들이 다. 양털을 깎을 때, 땀과 라놀린(양모에서 추출하는 오 일)로 인해 사용자의 핸들 그립을 방해한다. 이와 같은 경우를 대비해 중앙이 두꺼운 핸들을 사용함은 손바닥 안에서 핸들이 미끄러져 회전하는 것을 방지한다. $\mathrm{B}$ 는 삼각형 형태의 핸들이다. 이것은 모서리 두 부분이 화 살표 방향대로 손에 압력을 준다. 세 번째 $\mathrm{C}$ 는 타원 형

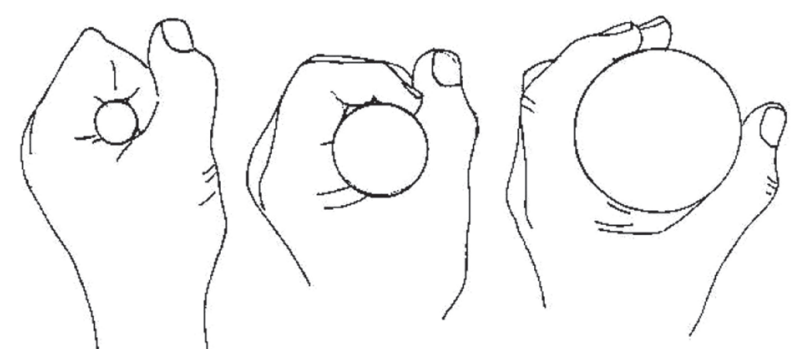

Fig. 12. Handle diameter can be specified for strongest grip. $^{19}$ 
A

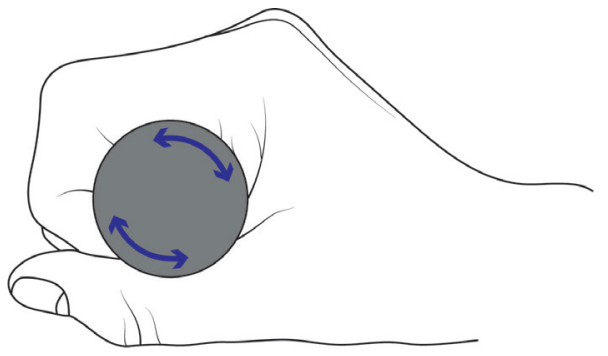

B

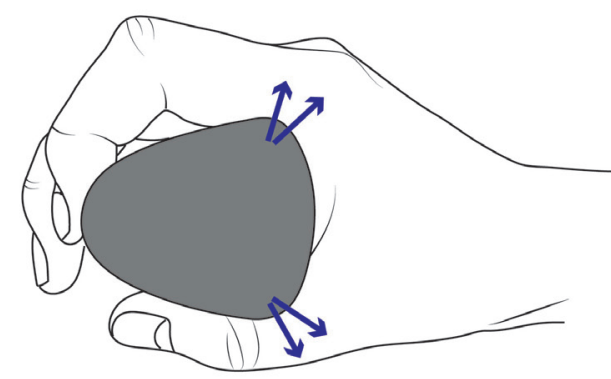

C

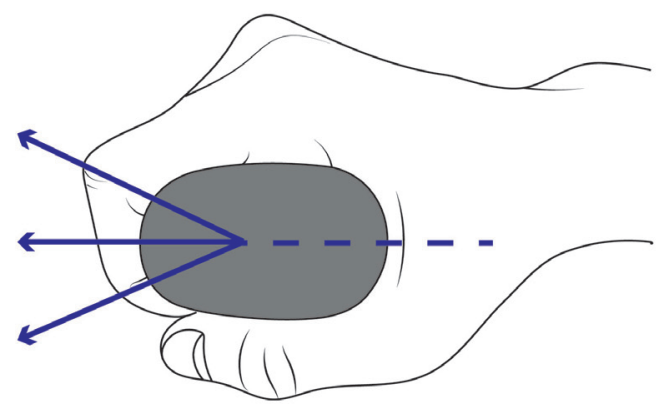

Fig. 13. Round (A), triangular (B), oval handle shape (C). ${ }^{30}$

태의 핸들로 가장 이상적인 형태의 그립과 마찰맞물림 (frictional engagement)이다. ${ }^{30}$ 엄지손가락을 핸들을 따 라 쭉 뻗어 힘을 주는 납작한 형태이며 납작한 형태의 핸들은 엄지 손가락과 나머지 손가락들이 원치 않게 비 틀어짐을 예방한다. ${ }^{31}$

\section{결언}

현재 시판되고 있는 대표적인 구내스캐너의 디자인 을 검토한 결과 총 타입 1종, 핸들 타입 3종, 펜 타입 3종 으로 분류할 수 있었다. 각각 스캐너들의 하드웨어적 제 원과 일부 스캐너 핸들의 크기와 무게를 그립 타입 별로 비교하였을 때, 공통점을 찾을 수 없었다. 또한, 구내스 캐너의 형태적 디자인인 하드웨어적 요소와 작동 원리 의 소프트웨어적 요소의 연관성은 스캐너의 타입 별 스
캔 작동원리가 각각 다르기 때문에 이번 조사에서 언급 하기 어려웠다. 다만 향후 스캔 작동원리가 통일된다면 인체공학적이고 사용자 친화적인 디자인이 더욱 각광받 을 것이라 예측되었다.

첫 번째 분류인 총 타입의 그립은 일반적으로 규정되 어 있는 그립 타입에 포함할 수 없는 특수한 경우로 분 류할 수 있다. 이 타입은, 힘을 분산시켜 어깨의 통증을 줄여주는 장점을 가지고 있으나, 하드웨어적으로 크기 가 커질 수 있어 사용자의 장시간 사용이 어려울 것이라 는 단점을 가지고 있다.

두 번째 핸들 타입에서 사용되는 power grip은 두꺼 운 물체를 잡을 때 많이 사용된다. 현재 의료 시장에도 핸들 타입의 제품들이 가장 보편적이고 대부분 power grip을 적용하고 있다. 다만, 이 경우를 구내스캐너에 적 용해봤을 때의 단점은 윗면, 양 옆면을 세밀하게 찍어야 하는 구내스캐너라는 정밀기기에서 의사가 자유롭게 작 은 움직임을 요구하는 작업에서 핸들을 회전하기에는 어렵다는 것이다.

반면, 마지막 펜 타입은 정밀한 작업이 필요한 분야에 가장 적합한 유형으로 핸들의 경량화가 해결된다면 구 내스캐너에 가장 알맞은 핸들의 형태로 보여 진다. 펜 타입에서 참고 도구로 핸드피스 목 부분을 보면, 구내스 캐너가 치아를 스캔할 때 유지해야 하는 일정한 거리를 만들 수 있는 각도를 참고 할 수 있다. 이것이 구내스캐 너의 팁 부분에 적용 가능성이 있다.

현재 의료계에서 수많은 기기들이 사용되고 있다. 그 중 특히 구내스캐너는 정확도와 정밀도가 요구되는 기 구로 지금까지 다양한 원리들이 적용되고 있다. 그 원리 들을 가진 스캐너를 최대로 활용하기 위해서는 소프트 웨어뿐 만 아니라 사용자 친화적인 디자인을 가지는 하 드웨어 역시 매우 중요하다. 사용자가 스캐너 사용 시 일어나는 불편함을 최대한 줄여줌으로써 기기 사용의 효율성을 극대화하고 오차 발생을 감소시키며 특히, 사 용자에게서 일어날 수 있는 근골격장애와 같은 질병을 예방할 수 있을 것이다. 이는 최종 사용자인 치과의사의 근로 환경을 개선하여 작업 생산성을 높일 뿐만 아니라 건강 유지를 통한 삶의 질 향상에도 도움이 될 것이다.

\section{Acknowledgments}

본 연구는 산업통상자원부의 재원으로 산업핵심기술 개발사업의 지원에 의하여 이루 어진 것임(10048888). 


\section{Orcid}

Hye-Nan Park http://orcid.org/0000-0002-7883-7949

Won-Hee Kim http://orcid.org/0000-0002-9216-1738

Young-Jun Lim http://orcid.org/0000-0003-2504-9671

Won-Jin Lee http://orcid.org/0000-0002-5977-6634

Jung-Suk Han http://orcid.org/0000-0002-9439-1465

Seung-Pyo Lee http://orcid.org/0000-0002-0103-6705

\section{References}

1. Marmaras N, Poulakakis G, Papakostopoulos V. Ergonomic design in ancient Greece. Appl Ergon 1999;30:361-8.

2. Gupta A, Bhat M, Mohammed T, Bansal N, Gupta G. Ergonomics in Dentistry. Int J Clin Pediatr Dent 2014;7:30-4.

3. Gopinadh A, Devi KN, Chiramana S, Manne P, Sampath A, Babu MS. Ergonomics and Musculoskeletal disorder: as an occupational hazard in dentistry. J Contemp Dent Pract 2013;14:299-303.

4. 3Shape. Available from: http://www.3shapedental. $\mathrm{com} /$ restoration/dental-clinic/trios-scanner/triosscanner/ (updated 2014 Nov 24).

5. iTero. Available from: http://www.itero.com/whyitero (updated $2014 \mathrm{Nov} 24)$.

6. 3D Progress. Available from: http://www. 3dprogress.it/product/3d-progress/ (updated 2014 Nov 24).

7. Orchestrate Orthodontic Technologies. Available from: http:// orchestrate3d.com/index.php/iosfastscan-3d-scanner/ (updated 2014 Nov 24).

8. Stephen Lim D.D.S. \& Associates. Available from: http://www.stephenlimdds.com/general-dentistrynew-york-ny/technology-e4d-new-york.html (updated 2014 Nov 24).

9. Schrijf je nu in. Available from: http://www.thcc. $\mathrm{nl} /$ site/pages/behandelingen/kronen-en-bruggen/ digitale-scanner.php (updated 2014 Nov 24).

10. Summit Dental Group. Available from: http://boise-dentists.com/service/introducing-cerec-digitalimpression-technology-at-summit-dental/ (updated 2014 Nov 24).

11. TRIOS ${ }^{\circledR} 3$ Shape TRIOS ${ }^{\circledR}$ Product Catalog. Copen- hagen, 3Shape; 2014. p. 18.

12. Pawley JB. Handbook of biological confocal microscopy. 3rd ed. New York; Springer; 2006.

13. Brooks R. Ergonomics Make Welders More Productive. Weld Design Fabr 2013.

14. iTero. iTero HD2.9 Operation Manual. Yehuda; CADENT LTD; 2012. p. 24.

15. 3D Progress. Available from: http://www.vatechkorea.com/cadcam/01_01.asp(updated 2014 Nov 24).

16. IOS Fastscan. Available from: http://orchestrate3d. com/index.php/ios-fastscan-3d-scanner/ (updated 2014 Nov 24).

17. Ali P, Behrai T. A reliable 3D laser triangulationbased scanner with a new simple but accurate procedure for finding scanner parameters. Am J Sci 2014;6:80-5.

18. El-Hakim SF, Beraldin JA, Blais F. Comparative evaluation of the performance of passive and active 3D vision systems. Proc. SPIE 26461995 doi: 10.1117/12.227862.

19. Patkin M. A check-List for handle design. Ergonomics Australia On-Line. 1997.

20. Patkin M. Ergonomic aspects of surgical dexterity. Med J Aust 1967;2:775-7.

21. Jonathan W, Choi YH. Ergonomic handle for grooming brush. US Patent 2003/6213055 B1.

22. Majid M, Alireza C, Mohammad AM, Shirazeh A. Ergonomic design of carpet weaving hand tools. Ini J Ind Ergonom 2007;37:581-7.

23. Lava ${ }^{\text {TM }}$ C.O.S. Lava ${ }^{\text {TM }}$ chairside oral scanner C.O.S. technical data sheet. St. Paul, MN; 3M ESPE; 2009. p. 8.

24. E4D Dentist. E4D dentist the difference in dentistry. Richardson, TX; D4D Technologies. Lls; 2011. p. 4.

25. Patkin M. Ergonomics and the operating microscope. Adv Ophthalmol 1978;37:53-63.

26. Heber S. 3D image reconstruction using active wavefront sampling. Available from: https://rvlab. icg.tugraz.at/project_page/project_wavefront/ project_wavefront.htm (updated 2014 Nov 25).

27. Derek T. Dental Handpiece. US Patent 2010/7677890 B2.

28. Colin R, Robert R. Ergonomic Device. US Patent 
2007/0196158 A1.

29. Drury CG. Handles for manual materials handling. Appl Ergon 1980;11:35-42.

30. Robert Bosch GmbH. Produktwissen-Reload. Available from: http://www.baumarktwissen.eu/ Medien/mdb/data/de/24063/24069/23679/ergonomie.html (updated 2014 Nov 25).

31. McCormick EJ. Human factors in engineering and design. 5th ed. New York; McGraw Hill; 1982. 


\section{사용자 친화적 인체공학에 따른 구내스캐너 디자인에 대한 고찰}

\section{박혜난 ${ }^{1}$, 김원희 ${ }^{1}$, 임영준 ${ }^{2}$, 이원진 ${ }^{3}$, 한중석 $^{2}$, 이승표 ${ }^{1 *}$}

${ }^{1}$ 서울대학교 치의학대학원 구강해부학교실

${ }^{2}$ 서울대학교 치의학대학원 치과보철학교실

${ }^{3}$ 서울대학교 치의학대학원 구강악안면방사선학교실

최근 치과 인상 채득법은 인상재를 사용하는 전통적 방법에서 구내스캐닝을 이용한 디지털 인상방법으로 빠르게 발전 하고 있다. 현재 치과시장에는 적어도 10 개 이상의 구내스캐너가 있다. 하지만 기술과 디자인이 빠르게 발전하는 가운 데 다양한 제품들 중 사용자가 합리적인 선택을 할 수 있는 기준이 명확하지 않다. 이 문헌고찰에서는 다양한 인체공학 적 디자인 관련 논문을 토대로 한 근거자료를 통하여 사용자의 입장에서 가장 사용이 편리하고 알맞은 인체공학적 디 자인을 제안하고자 한다. 이를 통하여 구내스캐너의 인체공학적 디자인의 중요성을 한번 더 확인하고 알맞은 인체공학 적 구내스캐너의 제시를 통하여 사용자(치과의사)들의 근골격의 질환과 장애를 예방하고자 한다.

(구강회복응용과학지 2015;31 (3):221-30)

주요어: 구강 스캐너; 인체공학; 핸들; 사용자 친화적 디자인 